\title{
The Experience of Male Physicians with Sexual and Gender-Based Harassment: a Qualitative Study
}

\author{
Amy H. Farkas, MD MSc ${ }^{7}$ (D), Cecilia Scholcoff, MD MPH' , Julie L. Machen, MD², \\ Cynthia Kay, MD MSc' ${ }^{7}$, Sarah Nickoloff, $\mathrm{MD}^{7}$, Kathlyn E. Fletcher, $M D \mathrm{MA}^{7}$, and \\ Jeffrey L. Jackson, MD MPH
}

'Division of General Internal Medicine, Medical College of Wisconsin, Milwaukee VA Medical Center, Milwaukee, WI, USA; ${ }^{2}$ Division of General Internal Medicine, Dell School of Medicine, University of Texas at Austin, Austin, TX, USA.

BACKGROUND: Sexual harassment and gender-based harassment are common in medicine; however, there is little in the literature regarding men's experience with gender-based and sexual harassment.

OBJECTIVE: The objective of this study was to better understand the experience men have with sexual and gender-based harassment in medicine.

DESIGN: We developed and piloted an interview guide based on a review of the literature and conducted semistructured interviews of male physicians, from trainees to attendings, at a tertiary care facility. Participants were recruited via email between April and August of 2019. These interviews were transcribed verbatim and, using an iterative coding approach based in grounded theory, were coded and analyzed for themes.

MAIN RESULTS: We conducted a total of 16 interviews. Five major themes were identified: (1) personal experiences of harassment, (2) witnessed harassment, (3) characterization of harassment, (4) impact of harassment, and (5) strategies for responding to harassment. The men reported experiences with sexual and gender-based harassment but were hesitant to define these encounters as such. They had minimal emotional distress from these encounters but worried about their professional reputation and lacked training for how to respond to these encounters. Many had also witnessed their female colleagues being harassed by both male patients and colleagues but did not respond to or stop the harassment when it originated from a colleague.

CONCLUSION: We found that men experience sexual harassment differently from women. Most notably, men report less emotional distress from these encounters and often do not define these events as harassment. However, similar to women, men feel unprepared to respond to episodes of harassment against themselves or others. Whether to deter sexual harassment against themselves, or, more commonly, against a female colleague, men can gain the tools to speak up and be part of the solution to sexual harassment in medicine.

KEY WORDS: sexual harassment; gender-based harassment; men.

Electronic supplementary material The online version of this article (https://doi.org/10.1007/s11606-020-05695-4) contains supplementary material, which is available to authorized users.

Received October 22, 2019

Accepted January 31, 2020

Published online February 19, 2020
J Gen Intern Med 35(8):2383-8

DOI: $10.1007 /$ s11606-020-05695-4

(c) Society of General Internal Medicine (This is a U.S. government work and not under copyright protection in the U.S.; foreign copyright protection may apply) 2020

\section{BACKGROUND}

Sexual and gender-based harassment has been well documented in the medical literature. However, much of the published literature is focused on the experiences of women and less about the experiences of men. In general, studies have found that men report lower rates of sexual and gender-based harassment, both in training and as faculty. In one study, $9.8 \%$ of male faculty reported experiencing gender bias versus $66.3 \%$ of the female faculty. Similarly, $4.2 \%$ of the male faculty reported experiencing harassment compared with $30.4 \%$ of female faculty ${ }^{1}$. A study of emergency medicine residents found that $8 \%$ of the men reported sexual harassment. However, another study found much higher rates, with $41.9 \%$ of the men reporting sexual harassment. ${ }^{2,3}$. This is in line with recent literature that demonstrates higher rates of sexual harassment, with $44.1-65.1 \%$ of men reporting at least one experience of sexual harassment ${ }^{4}$. These numbers suggest that gender-based harassment and sexual harassment are not uncommon among men in medicine and the variability highlights the need for further investigation.

Additionally, there is data to suggest that the negative effects of harassment, including worse mental health, higher burnout, and diminished job satisfaction, are consistent across genders, indicating that harassment is a significant problem for male physicians ${ }^{4,5}$. A limitation in the currently available literature is that all studies are survey based, making it unclear if the lower rates of sexual and gender-based harassment could in part be driven by how men define harassment in the workplace and by possible bias that tends to define gender discrimination and sexual harassment as a women's issue. Also, the use of survey data does not allow for a more nuanced exploration of men's experiences in the workplace.

The purpose of this study was to better understand the experience men have with sexual and gender-based harassment in medicine. 


\section{METHODS}

We conducted semi-structured interviews with male physicians of all levels of training at a tertiary, academic medical center. The purpose of these interviews was to assess their experiences with gender-based and sexual harassment. The study was approved by our IRB. Subjects received no incentive for participating.

\section{Participants and Recruitment}

The study was conducted between April and August of 2019. We recruited participants via an email which explained the study's purpose. Because residents rotate on a monthly basis through the facility, monthly emails were sent to the residents and General Medicine faculty. Additionally, given that there is specific literature from Emergency Medicine, targeted emails were sent to male Emergency Medicine faculty. Respondents were contacted by the study coordinator, who explained the project in more detail and arranged interviews by one of five interviewers (JL, CS, AF, CK, SN). None of the respondents left the study after agreeing to participate. All participants provided written informed consent prior to participation. As some of the interviewees were residents, efforts were made to ensure that they were interviewed by faculty who did not have a role in evaluating their clinical performance. Similarly, efforts were made to ensure that faculty who worked closely together were not paired for interviews.

\section{Interviews}

We developed an interview guide (supplement) based on a literature review and discussion among a panel of physicians with experience in the topic of sexual harassment. The interviews were piloted among a group of male attending physicians for flow, length, clarity, and content validity. The interview guide did not offer a specific definition of gender discrimination or sexual harassment but rather the questions were open-ended and asked about specific gender-based/sexual behaviors that the interviewees may have experienced with prompts that interviewers could use as follow-up questions. Participants were asked to define experiences themselves and to decide if they would call these experiences harassment. All interviewers were female physicians who had experience with qualitative interviewing. Interviews were conducted at a private location convenient for the interviewee, which most frequently was their office or the office of the interviewer. All interviews were audio-recorded and transcribed verbatim, with personal identifiers removed from the transcripts. Additionally, interviewers took field notes following the interviews. Interviews lasted an average of $24 \mathrm{~min}$. Participants did not review the transcriptions.

We continued recruitment until we reached thematic saturation, redundancy of identified themes ${ }^{6}$. A previous work has demonstrated that thematic saturation can be achieved in as few as 12 interviews ${ }^{7}$. We therefore planned on conducting $15-20$ interviews.

\section{Analysis}

A code book was created with an iterative coding approach using grounded theory ${ }^{8}, 9$. Grounded theory methodology focuses on allowing patterns to emerge and theories to be generated that are "grounded" in the data. This approach requires iterative data collection and analysis with constant comparison at each stage of data collection and analysis and careful decision-making ${ }^{10}$. Our previous work examining the experience of female physicians with sexual harassment also informed this work ${ }^{11}$. Coding began prior to the completion of the interviews. Two coders (AF, CS) reviewed the first four transcripts together, developing an initial coding scheme. This coding scheme was then applied to the remaining transcripts which were coded by one coder (AF). Once all transcripts were coded, the codes were then reorganized to major and minor themes. Coding was done with NVivo (v4, QSR International).

\section{RESULTS}

We conducted a total of 16 interviews. Six of the interviewees were attendings (4 from Emergency Medicine and 2 from Internal Medicine). Two interviewees were fellows (1 from Surgery and 1 from Internal Medicine). The remainder of the interviewees (8) were residents in Internal Medicine, of which 3 were chief residents. Five major themes emerged during our analysis Table 1.

\section{Theme 1: Personal Experiences of Harassment}

Most men reported experiencing some type of harassment. Many of these experiences involved comments on the physician's physical appearance or relationship status. One physician reported, "they'll comment on your look, then ask more questions: if you have a girlfriend, if you're married." Another reported "patients will comment if you happen to look nice, or talk about if you're good-looking or not." Physicians also noted that being asked out on dates was not uncommon.

A few men had experienced more overt sexual behaviors including sexual exposure, touch, and lewd comments. One man reported that female patients would unnecessarily expose themselves during the physical exam: "she was sitting on the table stark naked." Some physicians reported experiences in which women would make inappropriate comments during gynecological exams. One male attending discussed the experience of a male resident performing a gynecological exam on a female patient, "who was being very sexually inappropriate with him, and suggestive. That clearly shook him. He found that to be extremely distressing." Another expressed that female staff would make inappropriate sexual advances: "massaging shoulders, putting heads on shoulders, talking about their sex lives, inviting me out to drinks." One physician had an experience in which a female staff member grabbed his hand, looked at his wedding ring, and said "too bad" before walking away. Another 
Table 1 Five Major Themes with Representative Quotes

\begin{tabular}{|c|c|c|}
\hline Theme & Examples & Representative quotations \\
\hline Episodes of harassment & $\begin{array}{l}\text { - Comment on physical appearance } \\
\text { - Being asked out on date } \\
\text { - Sexually explicit comments }\end{array}$ & $\begin{array}{l}\text { "They'll comment on your look, then ask more questions, if you have a } \\
\text { girlfriend, if you are married" } \\
\text { "I think a lot of them revolved around probably pelvic exams or different } \\
\text { gynecologic complaints. The way people have referenced their body } \\
\text { parts." }\end{array}$ \\
\hline $\begin{array}{l}\text { Characterization of } \\
\text { harassment }\end{array}$ & $\begin{array}{l}\text { - Not sexual harassment } \\
\text { - A stressful encounter } \\
\text { - Harassment }\end{array}$ & $\begin{array}{l}\text { "It does not bother me in a way that I feel unsafe, or belittled, or } \\
\text { objectified. In that sense, I do not feel like it's necessarily sexual } \\
\text { harassment" } \\
\text { "a stressful sexual-related encounter, I do not know. So yeah, I think } \\
\text { harassment would maybe come into it." }\end{array}$ \\
\hline Impact of harassment & $\begin{array}{l}\text { - Causes little emotional distress } \\
\text { - Concerned about professionalism } \\
\text { - Viewed as compliment }\end{array}$ & $\begin{array}{l}\text { "It's not professional" } \\
\text { "I got a little nervous just because I do not expect it and then just remind } \\
\text { yourself that you have to be extra professional at the moment" } \\
\text { "maybe it's the maleness in me, but I tend to be flattered by those kind of } \\
\text { things" }\end{array}$ \\
\hline $\begin{array}{l}\text { Strategies to respond to } \\
\text { harassment }\end{array}$ & $\begin{array}{l}\text { - Humor } \\
\text { - Re-direction } \\
\text { - Use chaperone }\end{array}$ & $\begin{array}{l}\text { "Nervous laughing" } \\
\text { "I generally just try to change the subject to where it's off of me and more } \\
\text { back on them." } \\
\text { "I can recall some instances where I would, maybe the patient wasn't } \\
\text { requesting a chaperone, but I would ensure I would have it, based on } \\
\text { certain comments that they have made." }\end{array}$ \\
\hline Witnessed harassment & $\begin{array}{l}\text { - Patients harassing female colleagues } \\
\text { - Overhearing male colleagues make } \\
\text { inappropriate comments about female } \\
\text { colleagues }\end{array}$ & $\begin{array}{l}\text { "I've certainly been in the room when female peers have been harassed } \\
\text { by male patients." } \\
\text { "Sexist jokes are all over. It's pretty ubiquitous." } \\
\text { "She introduced herself to him and then he went on to comment about } \\
\text { how she looked, her appearance, how pretty she was, you know. It was } \\
\text { pretty graphic." } \\
\text { "Innumerable times, and in many different environments, I've heard male } \\
\text { colleagues comment on the physical attractiveness of female } \\
\text { coworkers... All the time. They would say things that they would not say } \\
\text { in front of the person" }\end{array}$ \\
\hline
\end{tabular}

physician reported direct comments from a female staff member on the attractiveness of his buttocks.

While our questions inquired only about gender-based and sexual harassment, a few men shared their experiences with harassment based on age and race. There were also a few men, at both the resident and attending levels, who struggled to identify specific experiences with harassment: "I'm having a hard time thinking of any specific instance."

\section{Theme 2: Witnessed Harassment}

When asked about witnessed harassment, there were two distinct themes the men described. One was witnessed harassment of female physicians and staff by patients and the other was overhearing male colleagues make inappropriate comments. With regard to witnessed harassment of female staff and colleagues, the interviewees commented that they had seen male patients say things like "sweetie, honey, go get me that pretty nurse." One man reported that these events "happen all the time." Another commented, "Sexist jokes are all over. It's pretty ubiquitous." Another interviewee had witnessed more explicit comments. He described an event that had occurred with his female resident during rounds, "she introduced herself to him and then he went on to comment about how she looked, her appearance, how pretty she was, you know. It was pretty graphic." Another reported that he had seen patients making comments "whether it be someone's ass, or breasts, or making comments they definitely shouldn't be."
As for witnessing male colleagues make inappropriate comments, one interviewee reported, "Innumerable times, and in many different environments, I've heard male colleagues comment on the physical attractiveness of female coworkers... All the time. They would say things that they wouldn't say in front of the person, but as soon as that person leaves hearing distance, that's happened more times than I can really even recall." When one physician was asked if he had witnessed these types of events, he responded "Yeah, for sure. The most common scenarios are...the locker room talk.... Just whenever a group of people get around, they'll talk about somebody they find attractive or something like that." Another witnessed his colleagues "talking about women's breasts when they're breastfeeding and how huge they are and wow."

\section{Theme 3: Characterization of Harassment}

When directly asked if they considered their personal experiences harassment, many of the interviewees said no but struggled to define these encounters. Some indicated that because they did not feel physically threatened in these situations they were not harassment, but they lacked other words to describe these encounters. One man said, "It doesn't bother me in a way that I feel unsafe, or belittled, or objectified. In that sense, I don't feel like it's necessarily sexual harassment." One interviewee stated, "I feel with harassment I would feel threatened," and went on to describe his encounter as a "stressful sexual-related encounter." Some men acknowledge that if in 
these same encounters the genders were flipped, they would likely qualify as harassment. "If the shoe were flipped, if these were comments a male was making to a female, I guess then I would consider it more harassment, and then well maybe this is harassment to me at an extent, but it doesn't feel harassing to me personally."

Some men did label their encounters, patients flirting with them or staff making comments on their appearance, as harassment. Other men acknowledge that the context of the encounter changed how they defined the event. These contextual factors included the presence or absence of a power differential as well as patients' level of impairment, either from intoxication or acute illness.

\section{Theme 4: Impact of Harassment}

In describing their emotional response to these encounters, the men commonly used words like "awkward," "flustered," and "surprised." Some felt that their position as a man inherently protected them: "well, I mean as a white man I've been relatively immune to it. I've had patients make inappropriate comments. But it doesn't make me terribly uncomfortable, because I'm in a position of authority over them. I've had nurses ... say or do things, that if I were to do it to them, it would clearly be harassment." While the men reported minimal distress from these incidents, many expressed that these events violated professional norms. One man stated, "you wouldn't say this to the person you get your coffee from." Another put it simply as "it's not professional."

While men reported minimal emotional impact from the experiences themselves, there was significant concern about how these events could impact their professional identity. Even though a woman made the inappropriate comments or behaviors, several men were concerned that if the incident was reported, they would not be believed or could even be blamed for the event because of their gender. One physician remembered thinking "my professional license and career and reputation could potentially be on the line for this kind of interaction." Men also worried about how their interactions may be perceived. "There's always a bit of concern that, if a female patient isn't happy with the way you're interacting or responding, that perhaps she could come up with allegations or say that you were being improper in any way." One reflected "I'm always afraid of where is the line and how do I make sure I stay on this side of the line," while another reported his frustration with untrue rumors that developed about a sexual relationship between himself and a nurse.

At other times, these encounters were viewed in a positive light by the man: "the fact that she was even flirting with me, made me think, alright, I'm still worthy of being flirted with." Another reported, "I guess I take it kind of as a compliment."

\section{Theme 5: Strategies to Respond to Harassment}

Most men reported using non-confrontational strategies for responding to these events. Many used humor, re-direction, or ignored the comments. One summed his response with: "nervous laugh and walk out the door," while another reported: "I generally just try to change the subject to where it's off me and more back on them." While none of the men reported changing their physical appearance, some did report being very cognizant of their professional demeanor during these events. One interviewee said, "just remind yourself that you have to be extra professional at this moment and, if you were being very friendly, to try and cut down a bit more on the friendlessness." Another said "try to make it as professional as possible." One man reported changing his interactions saying, "I try not to hug anybody, and then I shake hands, and I give people high fives, but then I try not to speak about things that are gender related."

Some physicians did report modifying the patient encounter in response to these events or in attempts to prevent encounters. Men reported ensuring a chaperone was present, leaving doors open, or bringing in other staff with them if they had a reason to be concerned about a patient's behavior. One physician did transfer the care of the patient to a female physician because of sexual comments the patient was making towards him. While not specifically related to sexual harassment or gender-based discrimination, other interviewees reported ending encounters early when they received abusive comments from patients.

In response to events of witnessed harassment, men were more likely to respond when the person being harassed was a trainee, either a medical student or resident. If it was a female colleague or staff member, the men reported deferring to the individual to respond first. When they witnessed male colleagues make inappropriate comments, the men reported that they simply would not involve themselves in the conversation. None reported speaking up or attempting to stop the behavior.

Almost universally the men reported a lack of training for how to respond to these events. When asked if he had received training, one put it simply: "absolutely never." One thought he may have had a lecture on difficult patient encounters during medical school and another acknowledged that he had completed required sexual harassment training modules. One physician did report, "I've seen female colleagues deal with it in a similar way. So, I guess I'd probably maybe I learned it from them."

\section{DISCUSSION}

Previous works examining sexual and gender-based harassment of men in medicine have been limited to surveys, and men have consistently reported fewer experiences with these issues. While most men in our study reported sexual or gender-based experiences, many were not threatened by these experiences and therefore did not define them as harassment. This is in contrast to our previous qualitative work with female physicians where they expressed significant distress from these encounters and were quick to label them as harassment ${ }^{11}$. The men still felt that these encounters were not professional, should not occur in the work 
place, and were bothered by them. A few of the men expressed that the lack of physical fear contributed to the lower level of emotional distress. Additionally, some of the men indicated that their gender alone placed them in a position of authority and hence protected them from harassment. This may, in part, explain why in survey data, men routinely report lower levels of gender bias and sexual harassment. Despite the lack of physical threat and emotional distress from these experiences, the men worried about the professional repercussions of these encounters and the impact on their professional reputation. They expressed concern that, because of their gender, they would be held responsible for the inappropriate encounter and not believed if the encounter was reported by the woman involved.

With regard to witnessed harassment, many of the men had seen female staff and colleagues experience harassment by patients and felt that this was a universal problem. It was also notable that many of the men had overheard their male colleagues making inappropriate comments about female physicians' physical appearance. These reports of witnessed harassment are consistent with the previous literature suggesting that gender-based harassment and sexual harassment are common in medicine ${ }^{1,2}, 12,13$. They are also consistent with our previous qualitative work with women in which, universally, the women reported experiencing some form of sexual or gender-based harassment ${ }^{11}$. Given that some male physicians witnessed colleagues make inappropriate comments about female physicians and staff when the women were not present, it is likely that the rate of harassment may be even higher than what is reported by female health care providers, as they can only report what they experience and may be unaware of comments made in their absence.

When it came to responses to incidents of harassment, the men generally used non-confrontational methods such as ignoring the comment, re-direction, or humor. This is similar to our previous work with female providers ${ }^{11}$. With regard to witnessed harassment, while the men in our study reported occasionally stepping in when they noticed a patient harassing a female colleague or staff member, none endorsed efforts to stop their male colleagues from making inappropriate comments. This may be in part due to a lack of training on how to handle these situations, which was reported by the majority of participants.

There is an increasing call to better prepare physicians for dealing with harassment in the workplace, particularly given its association with burnout ${ }^{5}$. While there are no published guidelines, several perspective pieces have proposed steps physicians can take to help mitigate harassment while acknowledging that there are professional obligations to patient care when the offender is a patient ${ }^{14-17}$. Additionally, mentors of medical trainees are obligated to report harassment under Title IX. We must ensure that those with educational roles understand these obligations and how best to help trainees.

There are limitations to our work. The men who volunteered to participate in our interviews may have been more likely to have sexual and gender-based experiences leading to selection bias. However, not all of the men interviewed endorsed these encounters. Additionally, this study reflects the experiences at one Midwestern tertiary care facility and the experiences at other institutions may vary. Additionally, we did not ask individuals to report their gender identity or sexual orientation and none disclosed this information in the process of the interview. These factors may contribute to the interpretation of experiences of gender discrimination and sexual harassment and could be explored further in future work. Finally, all interviewers were female, which may have impacted how men shared their experiences, though participants were offered the opportunity to be interviewed by a man.

There are several important lessons from this study. First, men appear to experience sexual harassment differently than women, often not defining such behavior as harassment. This raises the question of whether there is a universal definition of harassment. While there are legal definitions of harassment, such as the one from the US Equal Employment Opportunity Commission, this work indicates that there is significant variation in the personal interpretation of these behaviors. Efforts to reduce harassment in the workplace may require increasing awareness of the wide range of behaviors that may be considered harassment and the varied definitions and interpretations of harassment in the workplace. Secondly, the men universally endorsed a lack of training on how to deal with harassment, either when experienced firsthand or witnessed as bystanders. Future work in this area should develop and implement educational interventions to help men deal with and respond to incidents of harassment, both experienced and witnessed. Additionally, interventions should empower men to report both types of events, in hopes of changing the culture around gender discrimination and sexual harassment and improve the working environment for all.

Corresponding Author: Amy H. Farkas, MD MSc; Division of General Internal Medicine Medical College of Wisconsin, Milwaukee VA Medical Center, 5000 W National Ave, Milwaukee, WI 53295, USA (e-mail: ahfarkas@mcw.edu).

\section{Compliance with Ethical Standards:}

The study was approved by our IRB. All participants provided written informed consent prior to participation.

Conflict of Interest: The authors declare that they do not have a conflict of interest.

\section{REFERENCES}

1. Jagsi R, Griffith KA, Jones R, Perumalswami CR, Ubel P, Stewart A. Sexual Harassment and Discrimination Experiences of Academic Medical Faculty. Jama. 2016;315(19):2120-2121.

2. Li SF, Grant $\mathbf{K}$, Bhoj T, et al. Resident experience of abuse and harassment in emergency medicine: ten years later. J Emergency Med 2010;38(2):248-252. 
3. Schnapp BH, Slovis BH, Shah AD, et al. Workplace Violence and Harassment Against Emergency Medicine Residents. West J Emerg Med 2016;17(5):567-573.

4. Vargas EA, Brassel ST, Cortina LM, Settles IH, Johnson TRB, Jagsi R \#MedToo: A Large-Scale Examination of the Incidence and Impact of Sexual Harassment of Physicians and Other Faculty at an Academic Medical Center. J Womens Health (Larchmt). 2019.

5. Hu YY, Ellis RJ, Hewitt DB, et al. Discrimination, Abuse, Harassment, and Burnout in Surgical Residency Training. N Engl J Med 2019;381(18):1741-1752.

6. Ando H, Cousins R, Young C. Achieving Saturation in Thematic Analysis: Development and Refinement of a Codebook. Compr Psychol. 2014;3:03.CP.03.04

7. Guest G, Bunce A, Johnson L. How Many Interviews Are Enough?:An Experiment with Data Saturation and Variability. Field Methods 2006;18(1):59-82.

8. Corbin JM, Strauss A. Grounded theory research: Procedures, canons, and evaluative criteria. Qual Sociol 1990;13(1):3-21.

9. Crabtree BF MW. Doing qualitiative resarch. Thousand Oaks: Sage publications Inc; 1992.

10. Glaser BG, Strauss AL. The discovery of grounded theory : strategies for qualitative research. 2017.
11. Farkas A, Scholcoff, C, Kay, C, Lucas, J, Nickoloff, S, Fletcher, K, Jackson, JL. "Laugh and back out of the room": female physicians' strategies for dealing with sexual harassment by patients. J Gen Intern Med 2019;34:S101.

12. Sadrabad AZ, Bidarizerehpoosh F, Farahmand Rad R, Kariman $\mathbf{H}$, Hatamabadi H, Alimohammadi H. Residents' Experiences of Abuse and Harassment in Emergency Departments. J Interpers Violence 2016.

13. Fnais N, Soobiah $\mathbf{C}$, Chen $\mathbf{M H}$, et al. Harassment and discrimination in medical training: a systematic review and meta-analysis. Acad Med 2014;89(5):817-827.

14. Jagsi R. Sexual Harassment in Medicine - \#MeToo. N Engl J Med 2018;378(3):209-211.

15. Viglianti EM, Oliverio AL, Meeks LM. Sexual harassment and abuse: when the patient is the perpetrator. Lancet. 2018;392(10145):368-370.

16. Cowan AN. Inappropriate Behavior by Patients and Their Families-Call It OutInappropriate Behavior by Patients and Their Families-Call It OutInappropriate Behavior by Patients and Their Families-Call It Out. JAMA Intern Med 2018;178(11):1441-1441.

17. Alfandre D, Geppert C. Discriminatory and Sexually Inappropriate Remarks from Patients and their Challenge to Professionalism. Am J Med 2019.

Publisher's Note Springer Nature remains neutral with regard to jurisdictional claims in published maps and institutional affiliations. 